\title{
A FUNÇÃO SOCIAL DO ECOTURISMO
}

\author{
Philippe Pomier Layrargues*
}

\begin{abstract}
Eco-tourism represents a new segment of the tourist market that is drawing a great deal of attention on account of the relations it has fashioned with cultural and ecological dynamics. Nevertheless, its socio-economic context has remained relegated to second place in reflections on how to assess its limitations and potential. Based on the presumed need to draw up public policies of a distributive nature to face Brazil's concentration of income, this work sets out to analyze the social function of eco-tourism from the view-point of productive and commercial relations in order to see more clearly the role of eco-tourism in social change.
\end{abstract}

Keywords: Eco-Tourism; Sodial dhange; Public Policy; Distribution of income.

\section{INTRODUÇÃO: AS INTERFACES AMBIENTAL, CULTURAL E ECONÔMICA DO ECOTURISMO}

As justificativas que ressaltam a importância do ecoturismo no Brasil abrangem três dimensões: o papel desempenhado na proteção ambiental, nas trocas culturais e na geração de emprego e renda. Diante do promissor mercado que se anuncia para um breve futuro, o ecoturismo adquiriu destaque ultimamente não apenas na indústria do turismo, mas também no âmbito científico. Esse fenômeno social tem se revelado um atraente objeto de estudo para pesquisadores das ciências ambientais, que compreenderam suas íntimas relações - positivas ou negativas - com a proteção ambiental e a dinâmica cultural das comunidades envolvidas. Nesse contexto, dois temas adquiriram centralidade nos estudos relativos ao ecoturismo: os limites e possibilidades do ecoturismo com relação à proteção ambiental e com relação à dinâmica cultural.

Contudo, a terceira temática - a interface socioeconômica do ecoturismo - permanece ainda pouco explorada no âmbito científico; tendo em vista sua importância estratégica para o planejamento de políticas públicas sustentáveis de desenvolvimento local que também sejam capazes de promover distribuição de renda. Aqui, a questão central a ser formulada gira em torno das relações existentes entre o ecoturismo e a mudança social. É importante avaliar em que medida o ecoturismo pode contribuir para reverter o quadro da desigualdade social brasileira e promover distribuição de renda, sobretudo quando esse novo mercado afirma ser um gerador de emprego e renda.

O ecoturismo apresenta vínculos não apenas com a dimensão ambiental e cultural da sustentabilidade, mas também com a dimensão socioeconômica. E considerando que essa dinâmica carece de reflexão teórica, essa constatação serve de estímulo para um olhar analítico a respeito das relações entre o ecoturismo e a reprodução das condições sociais. Nesse sentido, esse texto objetiva discutir as relações estabelecidas entre o ecoturismo e a mudança social, apontando para uma justificativa em defesa da necessidade de criação de políticas públicas para o ecoturismo que definam explicitamente a sua função social.

\section{O ECOTURISMO E A MUDANÇA SOCIAL}

Sinteticamente, a discussão atual sobre o ecoturismo envolve duas preocupantes questões: sua relação com a proteção da natureza, entendido o ecoturismo como um instrumento de proteção ambiental pela via do mercado, focando sobretudo as questões relativas à capacidade suporte do ambiente para receber uma quantidade de visitantes adequada que não gere impactos ambientais negativos; e sua relação com a dinâmica cultural, entendido o ecoturismo como um vetor de aceleração de trocas culturais entre o viajante e o residente do espaço visitado pelo ecoturista, focando sobretudo as questões relativas às trocas culturais desiguais entre os visitantes e os moradores locais.

É satisfatório considerar o ecoturismo como uma possibilidade concreta tanto de proteção da natureza, como de fortalecimento cultural das comunidades habitantes no destino do ecoturista. Essa perspectiva não só é considerada como um dos princípios básicos norteadores do ecoturismo, ao referirem- se ao respeito à conservação ambiental e às comunidades locais, como também foi incorporada no próprio conceito de ecoturismo, que afirma ser esse um:

“segmento da atividade turística que utiliza, de forma sustentável, o patrimônio natural e cultural, incentiva sua conservação e busca a formação de uma consciência ambientalista através da interpretação do ambiente, promovendo o bem-estar das populações envolvidas." 1

Porém, estabelecer a preocupação com a proteção do patrimônio ambiental e cultural como princípio do ecoturismo pode ser satisfatório mas não é suficiente. Há uma outra questão, igualmente preocupante, que o ecoturismo envolve: é a sua relação estabelecida com fatores sócioeconômicos, fato que, afinal de contas, poderia chamar a atenção para se levantar a discussão a esse respeito, já que dois argumentos em defesa desse segmento da indústria do turismo mencionam diretamente a dimensão econômica. O primeiro deles diz respeito às oportunidades de negócio oriundas do novo mercado ecoturístico, que pode movimentar vultosas quantias de recursos financeiros. Frente às estimativas que consideram esse segmento do turismo como o que mais cresce no mundo, a uma taxa de mais de $20 \%$ ao ano, não há dúvidas que esse novo mercado altamente promissor seja capaz de gerar riquezas como poucas indústrias conseguem fazer. O mercado do ecoturismo brasileiro movimenta algo em torno de meio milhão de turistas e cerca de 500 milhões de reais ao ano, criando por volta de 30 mil empregos diretos. Contudo, como serão distribuídos 
os benefícios da riqueza gerada por essa indústria é uma questão que não está muito bem definida. Com quem ficará a volumosa movimentação econômica desse mercado ainda é uma preocupante incógnita. Essa dúvida nos remete então à segunda justificativa da importância econômica do ecoturismo para o Brasil, fornecendo indícios sobre a expectativa do mercado ecoturístico a respeito da distribuição dos benefícios econômicos do ecoturismo: afirma-se que o ecoturismo é um segmento do turismo capaz de ser um fator de geração de emprego e renda, que poderá beneficiar inúmeras comunidades rurais que possuem porculturais ções intactas de natureza com forte apelo estético capaz de se constituir num atrativo turístico.

Entretanto, mesmo com essa manifestação de boa intenção, é importante salientar que a própria definição do conceito de ecoturismo apresenta uma expressão vaga demais para precisar de que forma o ecoturismo pode promover o bem-estar e a melhoria da qualidade de vida das populações envolvidas. Diante das condições sociais brasileiras, que apresentam um preocupante quadro histórico de concentração de renda, e dado o potencial econômico desse novo mercado, o ecoturismo sobressai com uma importante função social a cumprir: ele pode ser considerado um relevante instrumento de distribuição de renda, mais engajado do que as tímidas menções que se referem à geração de emprego e renda ou melhoria da qualidade de vida das populações envolvidas, como benefícios econômicos indiretos do ecoturismo.

\section{A ECLOSÃO DA CRISE AMBIENTAL E A VALORIZAÇÃO DA ESTÉTICA DA NATUREZA}

Para iniciar essa reflexão que tece relações do ecoturismo com a mudança social, é preciso entender o ecoturismo sob uma perspectiva pouco usual, onde ele aparece como um fenômeno social oriundo de uma situação muito peculiar desde que a crise ambiental eclodiu nas sociedades modernas.

A crise ambiental apresentou o mérito de ter afetado, mas não destituído, muitos dos valores do projeto central da modernidade, que se constitui na valoração do artificial em detrimento do natural, onde a natureza, que antes era objeto de apropriação e exploração, passa a ser positivamente valorada frente ao panorama de escassez de recursos naturais. Nesse sentido, é razoável partir do pressuposto de que o ecoturismo corresponde a um fenômeno social eminentemente decorrente da eclosão da crise ambiental, onde a relação entre o ambiente artificial e o ambiente natural assume novos e intrincados contornos em termos de valoração simbólica. Por conseguinte, a nova alteridade natural- artificial provoca novos significados para o viajante que procura o exótico, o diferente. Assim, um novo horizonte de destinos se abre ao turismo, ampliando as possibilidades de viagens, agora também para a natureza.

Em outras palavras, uma das variáveis que tornou possível e viável o fenômeno ecoturístico foi a nova polarização dos valores sociais conferidos para o espaço urbano e para o espaço natural. O espaço natural tornou-se o novo objeto de desejo do viajante, imbuído da necessidade de contato e alteridade com as origens, a pureza, a ordem, o ritmo e a estética natural. A nova subjetividade engendrada pela escassez de natureza, acompanhada pela valorização da estética da natureza, parece ser fator suficientemente forte para explicar porque esse é um novo e promissor mercado, o segmento da indústria do turismo que apresenta comparativamente o maior crescimento dentro do setor turístico.

$\mathrm{O}$ ecoturismo é um sintoma da mudança de paradigma. A repugnante, inóspita e assustadora natureza, que antes era qualificada como "mato" ou "selva", virou "floresta". Desse modo, essa atividade produtiva só foi possível florescer depois que a construção social da natureza retirou o seu caráter "selvagem", para torná-la atraente e acolhedora. De dominada e explorada, quando adquiria valor apenas se transformada pelo trabalho humano, passou a ser venerada e reverenciada, alvo de romarias e peregrinações para verdadeiros "santuários ecológicos” ainda preservados no país.

\section{O ECOTURISMO COMO UM NOVO MERCADO}

Se o ecoturismo não envolvesse a variável econômica, ele poderia ser um mero instrumento de proteção do patrimônio ambiental e cultural. Mas como a produção do valor simbólico para a natureza foi registrada pelo mercado como uma nova oportunidade de negócio, e esse valor simbólico foi materializado como um mercado ecoturístico, permeado por relações mercantis em torno da mercadoria "natureza esteticamente atraente", o ecoturismo se caracteriza por ser o dinamizador de um novo mercado que carrega em si o potencial de produzir efeitos colaterais positivos, como a proteção ambiental e cultural. Evidentemente, dependendo do enfoque, o ecoturismo pode ser entendido sob as duas perspectivas, que do ponto de vista ideológico, disputam legitimidade interpretativa sobre seu significado. Contudo, uma abordagem complexa do fenômeno do ecoturismo ressalta as relações sociais em torno dessa mercadoria, exigindo portanto, a realização de leituras adequadas a essa realidade. A omissão da variável socioeconômica do ecoturismo resulta num processo de alienação das relações sociais que permeiam esse mercado, resultando em posturas políticas simplistas e ingênuas, por desconsiderar então as relações que o ecoturismo estabelece com a mudança social.

Em suma, o ecoturismo é um fenômeno, se não eminentemente econômico, pelo menos fortemente determinado por condicionantes econômicos que direcionam não apenas as tendências de crescimento desse mercado como também os mecanismos de reprodução social. Em outras palavras, se a natureza se tornou uma nova mercadoria, o ecoturismo representa a criação de um novo mercado, possibilitado em função da eclosão da crise ambiental que apresentou como efeito subjetivo, a criação de uma nova sensibilidade capaz de fornecer um valor estético positivo à natureza. A natureza como uma nova mercadoria passa por uma outra onda de apropriação pelo mercado, mas dessa vez, não dos produtos gerados, mas dos serviços prestados, a exemplo da contemplação estética da beleza natural.

\section{AS RELAÇÕES PRODUTIVAS E MERCANTIS NO MERCADO ECOTURÍSTICO}

E como se estrutura esse mercado? Quais são e como se comportam, trocando em miúdos, os agentes encarregados das relações produtivas (relações entre capital e trabalho)? O ecoturismo é uma nova atividade econômica que tem a natureza como mercadoria, embora essa mercadoria não seja produzida por ele, mas sim pela própria natureza. A natureza é considerada por alguns sociólogos ambientais como a "terceira força produtiva", como uma alusão às duas outras forças que movimentam o circuito produtivo: o 
capital e o trabalho. Dada então a capacidade recentemente reconhecida da produção de serviços ambientais pela natureza com utilidade para o ser humano, a natureza se configura então como a terceira força produtiva.

Ou seja, a singularidade do ecoturismo como indústria capitalista é que ele transaciona uma mercadoria praticamente autoproduzida: ela é natural, e não socialmente produzida, mas mantida ou incrementada pelas comunidades ali residentes. Cabe ao empreendedor ecoturístico, como proprietário da mercadoria, apenas a tarefa de humanizar a paisagem, prover a infra-estrutura de acolhimento dos visitantes, a logística da viagem e condução do visitante pelo interior do santuário. O trabalho humano, realizado frequentemente pelos moradores locais como mão-deobra trabalhadora, se resume em acrescentar um toque de "civilidade" através de trilhas interpretativas, passarelas, pontes suspensas, torres de observação, mirantes, centros de recepção de visitantes, etc. O viajante ecoturista ocupa o espaço do consumidor, que entra no circuito através das relações mercantis estabelecidas com o empreendedor ecoturístico ao oferecer o pacote a seu cliente.

Como todo mercado, o ecoturismo não está isento da busca da economia de escala, que se caracteriza, no caso do turismo, no consumo de massas. Nesse sentido, o ecoturismo se qualifica como um voraz consumidor de espaços, colocando- o à mercê do dilema econômico- ecológico, caracterizado pelo balanço entre a maximização dos investimentos sem o comprometimento da capacidade suporte ideal. A sustentabilidade do negócio ecoturístico depende em grande medida da capacidade de se encontrar esse ponto de equilíbrio.

\section{EDUCAÇÃO AMBIENTAL COMO COMPENSAÇÃO DO RISCO DO MERCADO ECOTURÍSTICO}

O ecoturismo é tradicionalmente considerado um veículo da educação ambiental, encarregado sobretudo da sensibilização e aquisição de conhecimentos ecológicos. Por outro lado, considerando os riscos do ecoturismo que podem comprometer sua própria sustentabilidade, a educação ambiental se transforma em veículo do ecoturismo. Assim, a educação ambiental no contexto do ecoturismo, assume novos contornos no que diz respeito às suas metas, pois agora, a importância de uma eficaz sensibilização do turista com relação à proteção ambiental e cultural do espaço visitado, necessária para a natureza e a comunidade local, também se refere à sustentabilidade do próprio negócio ecoturístico.

A despeito dos benefícios que o ecoturismo apresenta, há que se considerar o que se convenciona chamar de "efeito colateral" mas que na verdade é a própria característica da mercantilização da natureza: o duplo risco da atividade (ultrapassar a capacidade suporte do ambiente e provocar a desestruturação cultural da comunidade local). Tais riscos são sublimados pela expectativa de que o papel da educação ambiental seja justamente o controle desses "efeitos colaterais". Por isso enfatizamos que o mercado ecoturístico apresenta um potencial para proteger o patrimônio natural e cultural. A proteção desses patrimônios não é inerente ao ecoturismo, mas dependente da educação ambiental.

Assim, a educação ambiental assume aqui um papel de maior importância tanto para refrear uma sobrecarga de visitantes que poderia afetar a capacidade suporte do ambiente, como para minimizar a possível desestruturação da cultura local. Nesse sentido, a educação ambiental aplicada ao ecoturismo caracteriza-se por ser um mecanismo de compensação do risco da atividade econômica, provendo a segurança necessária para que o sucesso do negócio ecoturístico de hoje não signifique o seu fracasso amanhã.

\section{OS MODELOS DE ECOTURISMO}

Sob essa perspectiva que envolve uma dinâmica de correlação de forças entre capital e trabalho, existem dois modelos de ecoturismo, que devem ser aqui entendidos como duas categorias possíveis apenas como tipo-ideal, ou seja, que representam pares binários que no real podem conter elementos comuns imbricados entre si: o ecoturismo empreendedor e o ecoturismo de base comunitária, cujas características básicas estão descritas no quadro a seguir. 


\section{ECOTURISMO DE BASE COMUNITÁRIA}

A comunidade local es a própria operadora do negócio ecoturístico, permitindo o desenvolvimento comunitario local, a emancipaçăo politica e favorecendo a distribuição de renda.

A renda gerada permanece na comunidade local e $\epsilon$ distribuida entre os trabalhadores da atividade.

$\mathrm{Ha}$ espaço para inclusão e inclusive ascensåo social, ja que a própria comunidade local é responsavel pela gestão da atividade.

\section{- pacote ecoturistico envolve multiplas dimensoles:} natureza, história e cultura como variáveis indissociadas. Locais de destino sào sobretudo comunidades extrativistas.

turista imerge na realidade local real, se impregna da vida cotidiana da coletividade, vivencia o envolvimento profundo e legitimo da rotina da comunidade local naquele espaço protegido. $O$ turista experimenta a alteridade de si com o outro como continuidade da natureza.

turista experimenta um contato direto com a realidade. com pouca mediaçăo do guia.

\section{ECOTURISMO EMPREENDEDOR}

A operadora do negócio ecoturístico nảo é proveniente da comunidade local, mas de centros urbanos, o que dificulta a distribuição de renda.

A renda gerada $e$ destinada ao lucro dos empreendedores que financiam a atividade.

Fala-se de oportunidade de geraçăo de emprego para a comunidade local. para ocupar funçoes de serviços, mas nåo de empreendimento.

O pacote ecoturistico privilegia a beleza natural. Locais de destino sảo sobretudo os 'hotéis de selva'.

turista imerge numa realidade fantasiosa, vivencia um contato idealizado de uma natureza idflica, virgem e dadivosa, de forma superficial e folclorica. $O$ turista experimenta apenas a alteridade de si com a natureza exposta numa vitrine.

turista experimenta um contato indireto com a realidade, com forte mediaçăo do guia.

Diante desse quadro que expõe os modelos de ecoturismo, torna-se necessário reconhecer que enquanto o ecoturismo de base comunitária possibilita converter os fatores socioeconômicos em favor da mudança social, o ecoturismo empreendedor age em função da manutenção das condições sociais historicamente inalteradas.

Nesse sentido, é interessante ainda tecer considerações a respeito da formação profissional de recursos humanos para atuar no ecoturismo. Dependendo do enfoque que se implemente, é possível identificar duas possibilidades, de acordo com os dois modelos: uma que prepara recursos humanos para geração de empregos (considerados como trabalhadores subordinados ao capital) para o ecoturismo empreendedor, outra que prepara recursos humanos para ascensão social (considerados como trabalhadores em busca da emancipação política e autonomia econômica), para o ecoturismo de base comunitária. Para uns, cursos de culinária, recepção, hospedagem, guia, entre outros, que mantêm inalterada a relação capital e trabalho; para outros, cursos de associativismo, empreendedorismo e gestão de negócios, além, evidentemente,de linhas de crédito popular, subsidiando a mudança social.

\section{A FUNÇÃO SOCIAL DO ECOTURISMO RESGATADAEM POLÍTICAS PÚBLICAS}

O potencial de mercado do ecoturismo no Brasil é enorme e promissor. Resta saber se teremos capacidade de aproveitá-lo não só como um valioso instrumento de proteção do patrimônio ambiental e cultural, mas também como uma oportunidade de promoção de ascensão social e distribuição de renda.

O mercado capitalista produziu valor destruindo a natureza, e seu caráter cíclico agora o faz produzir valor protegendo a natureza. A questão não é saber das verdadeiras intenções do mercado no que diz respeito à proteção do patrimônio natural e cultural, mas como será repartida a riqueza gerada pela exploração econômica da natureza protegida. A história tem evidenciado que o mercado não conseguiu distribuir a riqueza gerada pela exploração da natureza, quando esta só adquiria valor enquanto produto transformado pelo trabalho humano. Terá ele agora capacidade de distribuir a riqueza gerada pela nova onda de exploração da natureza? Tendencialmente, o mercado pode ser um bom alocador de recursos, mas não é um bom mecanismo de justiça distributiva, já que a balança do poder no mercado livre pende sempre em favor do capital.

Do problema que procuramos discutir à idéia que procuramos defender, torna-se explícito o importante papel que as políticas públicas assumem como vetor distributivo para equilibrar as forças do mercado, que por si só, já provaram não serem capazes de repartir a riqueza gerada pela exploração econômica da natureza. Urge que sejam criadas políticas públicas voltadas ao ecoturismo que sejam de caráter distributivo, onde A respeito da formação profissional, é possível identificar duas possibilidades: uma que prepara para geração de empregos, outra que prepara para ascensão social. sejam contempladas não apenas a dimensão ambiental e cultural mas também a socioeconômica da sustentabilidade.

O potencial do mercado do ecoturismo para produzir efeitos colaterais positivos se torna de fato efetivo, pela atuação do livre mercado sem o controle efetuado por políticas públicas, porque transaciona uma mercadoria que para ser consumida, 
inerentemente precisa ter incorporada essas qualidades adicionais, a proteção ambiental e cultural, condicionantes do sucesso do negócio. Mas, desde que acompanhado de eficazes programas de educação ambiental. Contudo, a função social do ecoturismo, quer seja, a justa repartição dos benefícios advindos da riqueza gerada por esse mercado, só pode ser alcançada com algum controle social que regule as relações sociais em condições de igualdade.

Políticas públicas liberais e conservadoras podem ter como meta a "geração de emprego e renda", investindo por conseguinte, em modelos de ecoturismo empreendedor; já as políticas públicas progressistas e emancipatórias podem ter como meta a "ascensão social e a distribuição de renda", investindo portanto, em modelos de ecoturismo de base comunitária. O ecoturismo pode ser apenas uma estratégia a mais de conservação da natureza ou um mecanismo de desenvolvimento social que integre a variável ambiental, dependendo do planejamento proposto pelas forças políticas. Enquanto a primeira opção procura não alterar as condições sociais já consolidadas, que normalmente apresentam relações produtivas e mercantis tendenciosamente desequilibradas na balança do poder em favor do capital, a segunda opção procura justamente reverter esse quadro, agindo em favor de um maior equilíbrio nessa relação assimétrica de poder. Eis o verdadeiro papel do Estado como formulador de políticas públicas, eis uma excelente oportunidade para o país, ao mesmo tempo em que protege sua natureza através de uma atividade econômica de baixo impacto ambiental, promover a justiça social.

O ecoturismo não está à margem das condições de reprodução social, já que ele é permeado por relações produtivas e mercantis, notadamente determinadas pelo livre mercado. Ele é um instrumento ideológico que, por intermédio de qualquer relação social mediada pelo capital, pode agir seja em função da conservação ou da transformação social, dependendo do que se decida como diretriz política para o ecoturismo. Daí o apelo para a necessidade de se criar políticas públicas capazes de definir a função social do ecoturismo.

\section{NOTAS}

1 Brasil. Diretrizes para a Política Nacional de Ecoturismo. Brasília: MMA/ MICT. 1994.

* Biólogo pela Universidade Santa Úrsula. Especialista em Educação Ambiental pela Universidade Federal Fluminense. Mestre em psicologia social pela Universidade Federal do Rio de Janeiro (Centro de Filosofia e Ciêncais Humanas) e Doutor em Ciências Sociais pela Universidade Estadual de Campinas (Instituto de Filosofia e Ciências Sociais). Gerente de Projetos Diretoria de Educação Ambiental do Ministério do Meio Ambiente.

Participou do Prêmio Sesc-Senac de Turismo Sustentável, realizado em outubro de 2002.

E-mail: philippe.layrargues@mma.gov.br.

Recebido para publicação em: 17/02/04. 